\title{
Lições de coisas: Concepção científica e projeto modernizador para a sociedade
}

\author{
Vera Teresa Valdemarin ${ }^{\star \star}$
}

\begin{abstract}
RESUMO: O objetivo deste artigo é compreender alguns aspectos da cultura escolar, assinalando a seleção de valores culturais, econômicos e educacionais operada pela instrução escolar, com base na análise de manuais didáticos para uso de professores, elaborados nas décadas finais do século XIX e fundamentados no Método de Ensino Intuitivo ou Lições de Coisas. Embora expressem a mesma fundamentação filosófica, os manuais apresentam diferentes procedimentos para o ensino dos conteúdos escolares que se configuram como visões específicas do progresso científico. Vinculados ao projeto modernizador da sociedade, em curso no século XIX, as diferenças apresentadas pelos manuais nos informam sobre as diversas vertentes constitutivas desse projeto.
\end{abstract}

Palavras-chave: Lições de coisas, método de ensino intuitivo, cultura escolar, transposição didática, manuais de ensino

\section{Introdução}

Eric Hobsbawm (1997) inclui a criação da instituição escolar moderna entre as "tradições inventadas" no século XIX com o objetivo de inculcar

\footnotetext{
* Este artigo contempla resultados parciais do projeto de pesquisa "Estudando as 'Lições de Coisas'”, financiado pelo CNPq e pela Fapesp.

** Professora Assistente Doutora - Departamento de Ciências da Educação - Programa de PósGraduação em Educação Escolar - Faculdade de Ciências e Letras/Unesp/Campus de Araraquara.
} 
valores e normas de comportamento então nascentes, por meio de um conjunto de práticas, cujos princípios e conteúdo serviriam à coesão social e à legitimação hierárquica. Essa instituição, "equivalente secular da Igreja", com seus graus de instrução - primário, secundário e superior -, que além de definir a progressão no conhecimento, passaria a fornecer um critério para a inclusão nas classes sociais e, conseqüentemente, nas decisões políticas, é descrita nos seguintes termos:

\begin{abstract}
A escolarização fornecia não só um meio conveniente de comparação entre indivíduos e famílias sem relações pessoais iniciais e, numa escala nacional, uma forma de estabelecer padrões comuns de comportamentos e valores ... Além disso, permitia, dentro de certos limites, a possibilidade de expansão para uma elite da classe média alta, socializada de alguma maneira devidamente aceitável. Aliás, a educação no século XIX tornouse o mais conveniente e universal critério para determinar a estratificação social, embora não se possa definir com precisão quando isto aconteceu. A simples educação primária fatalmente classificava uma pessoa como membro das classes inferiores. O critério mínimo para que alguém pudesse ter status de classe média reconhecido era educação secundária a partir de, aproximadamente, 14 a 16 anos. A educação superior, exceto por certas formas de instrução estritamente vocacional, era sem dúvida um passaporte para a alta classe média e outras elites. (Hobsbawm 1997, p. 301)
\end{abstract}

A análise de Hobsbawm pontua historicamente a justificativa para a disseminação da escolarização e, de modo mais significativo, a formação cultural como um critério diferenciador entre os diversos grupos pertencentes a uma mesma sociedade. Assim sendo, pode-se afirmar que a difusão diferenciada da cultura entre a população passa a caracterizar a função social da escola, a fim de legitimar o pertencimento social e a propagação de determinados valores.

Entretanto, a análise da cultura que a escola transmite a seus alunos comporta, além da clivagem histórico-social, a análise propriamente pedagógica ou interna, que engloba o programa escolar, com as finalidades educativas que lhe são confiadas, o conteúdo aprendido e também objetivos não explicitados, decorrentes dos mecanismos didáticos postos em ação para o ensino, isto é, o modo como os conceitos são aprendidos (Chervel 1998). Nessa perspectiva, tem sido problematizado o papel do ensino na 
formação de determinados tipos de raciocínio e de pensamento e, segundo Bourdieu (1992), a escola opera em diferentes níveis para a transmissão da cultura, a fim de produzir, implícita ou explicitamente, o consenso cultural. Sua grande força influenciadora proviria da constituição de determinados hábitos mentais e da criação de disposição para gerar esquemas interpretativos suscetíveis de serem aplicados em diferentes campos de conhecimento e de ação, que poderiam ser generalizados como "hábito culto". Assim sendo, pode-se apontar a existência de um forte vínculo entre as escolas de pensamento e a cultura de uma classe social específica, pois os esquemas de pensamento provenientes de concepções teóricas, adotados pela escola como consensuais, seriam a expressão de uma determinada classe social, que passa a ser referência para modelos de pensar e constituir problemáticas.

Bourdieu afirma também que, entre os elementos determinantes desse processo de inculcação de modos de pensar e de sistemas de pensamento, podem ser incluídos o processo de aquisição de saberes, a natureza dos exercícios, lições e tarefas que foram impostos aos alunos, as provas a que se submeteram, os critérios segundo os quais foram julgados e o tipo de relação estabelecida entre os alunos e os professores e/ou representantes da administração escolar, criando, por meio de tais mecanismos, um elo de cumplicidade entre os membros de uma mesma classe social, participantes do mesmo processo.

Tendo por base essas orientações teóricas que problematizam os resultados da transmissão cultural realizada pela escolarização, este artigo dedica-se à análise de alguns elementos da cultura escolar, tentando estabelecer, ainda que hipoteticamente, implicações da adoção de diferentes procedimentos didáticos para o ensino de conceitos, seus modos de transmissão, exercícios propostos e organização de lições, delimitados ao Método de Ensino Intuitivo, criação do século XIX, período da invenção da escola moderna.

O Método de Ensino Intuitivo, dada sua pretensão de constituir-se na base para a modernização da forma de ensinar (Souza 1998; Giolitto 1983), substituindo o caráter abstrato e pouco utilitário da instrução, impulsionou a produção de inúmeros manuais, destinados a alunos e professores, exemplificando procedimentos e conteúdos de ensino capazes de concretizar as inovações pretendidas. Nesses manuais são explicitados os princípios sobre o conhecimento nos quais se fundamenta o método, que podem ser assim sintetizados: o ato de conhecer tem início nas operações dos sentidos sobre o mundo exterior, a partir das quais são 
produzidas sensações e percepções sobre fatos e objetos que constituem a matéria-prima das idéias. As idéias assim adquiridas são armazenadas na memória e examinadas pelo raciocínio, a fim de produzir o julgamento.

Consoantes a essa concepção epistemológica, as atividades de ensino devem ser iniciadas com as operações dos sentidos, principais instrumentos da aprendizagem, observando-se fatos e objetos que produzirão idéias, reflexão e sua expressão em palavras. Devido ao uso dos objetos, à observação e ao resultado projetado, este método é considerado por seus propositores como sendo concreto, racional e ativo.

Nessa proposição, o processo de ensino deve desenvolver-se do simples para o complexo, do que se sabe para o que se ignora, dos fatos para as causas, das coisas para os nomes, das idéias para as palavras, dos princípios para as regras, ou seja, do que pode ser observado para a abstração. Assim sendo, observar é progredir das percepções dos sentidos para a idéia, do concreto para o abstrato, dos sentidos para a inteligência, dos dados para o julgamento, por meio de atividades concretas que são, ao mesmo tempo, expressão do pensamento e da experiência. Dada a proposição de que os sentidos são os instrumentos determinantes para a aquisição do conhecimento, os objetos a serem utilizados no ensino, isto é, postos para serem observados, assumem papel fundamental, pois são a garantia de que o conhecimento não seja meramente transmitido, mas gerado com base no contato com o objeto.

Embora os manuais intitulados Lições de Coisas, produzidos nesse período, expressem os mesmos princípios epistemológicos, seja em seus prefácios, seja nas instruções de uso, seja nas lições dedicadas à descrição da importância dos sentidos humanos, a forma de concretizar esses princípios, traduzindo-os em atividades didáticas, apresenta diversidade de procedimentos. Ou, dito de outra forma, sob as expressões "lições de coisas" ou "método de ensino intuitivo" há prescrições de conteúdos e de procedimentos didáticos que variam da coerência com a concepção epistemológica até sua contradição.

A análise interna da cultura ensinada na escola, portanto, pode incidir também sobre a formalização de concepções sobre o conhecimento num rol de atividades e de situações de aprendizagem, tarefa à qual se propõem os manuais de ensino e que constitui o núcleo da transposição didática. A primeira etapa desse processo, no qual o conhecimento recebe um tratamento didático para constituir-se no saber a ser ensinado (Chevallard 1985), consiste na seleção do conhecimento, isto é, na valorização explícita de alguns conteúdos 
em detrimento de outros, seguida da definição dos conceitos essenciais à compreensão de determinado campo de saber, das noções relativas a esses saberes, bem como das noções primitivas, próximas ao saber fazer e ao saber aplicar os conceitos postos para aprendizagem. Essas noções, em geral, não são reconhecidas como objetos de ensino, mas, no entanto, são pré-requisitos para a aprendizagem e podem ser descritas como: formular questões, analisar e conceituar problemas, definir problemas e objetivos, descobrir modelos e similares, reunir dados, experimentar, transferir habilidades e estratégias para novas situações, aplicar conhecimentos (Chevallard 1985). Esse mesmo autor adverte que, em geral, os manuais de ensino não atentam para dois aspectos importantes no processo de transposição didática: a exigência de domínio de pré-requisitos sobre o conhecimento a ser ensinado e a tensão entre velho e novo na aprendizagem. O conteúdo a ser ensinado, embora seja uma parte da cultura estabelecida socialmente, deve aparecer ao aluno como um dado novo e desconhecido, pois é essa condição que permite o estabelecimento do contrato didático entre quem ensina e quem aprende. Numa segunda etapa, esse dado deve estar inserido no contexto do que já é conhecido, tornando-se a base para aquisições subseqüentes e inserindo-se num ciclo de estudos que tem a renovação como elemento constituinte e assume novas formas e progressões nos programas, nos manuais e na atividade do professor em sala de aula.

Com base nessas referências teóricas, pretendemos analisar a cultura escolar na perspectiva da transposição didática, tomando como fonte os seguintes manuais de ensino: Lições de cousas, de autoria do Dr. Saffray, publicado em 1908; Plan d'études et leçons de choses, de Jules Paroz, publicado em 1875; Exercises et travaux pour les enfants selon la méthode et les procedés de Pestalozzi et de Froebel, de autoria de Fanny Ch. Delon e M. Delon, em edições de 1892 e 1913 e Primeiras lições de coisas, de Norman Allison Calkins, publicado em 1886, todos difundidos nas escolas e para os professores brasileiros.

\section{A transformação dos pressupostos teóricos em procedimentos didáticos}

A análise dos manuais centra-se na ênfase que cada autor atribui à observação e à experimentação e, por conseguinte, ao uso dos sentidos, uma vez que tais atividades são o ponto de partida para o conhecimento, 
segundo os princípios epistemológicos do Método de Ensino Intuitivo. Os textos são cotejados também conforme a utilização de coisas ou objetos na aprendizagem, na formação de idéias e no desenvolvimento da capacidade de julgamento. E, finalmente, considera-se a diferença entre os manuais quanto à imagem da cultura que veiculam, incluindo o conteúdo a ser ensinado, os pré-requisitos e os hábitos mentais daí decorrentes. Em síntese, pretende-se que esses critérios de análise possam evidenciar o processo de transposição didática referenciado ao Método de Ensino Intuitivo e parte da cultura escolar elaborada no século XIX.

Os manuais analisados são unânimes na afirmação da importância dos sentidos para a aprendizagem, com o conseqüente privilegiamento da observação e da experiência como atividades cognitivas, e daí decorre a primeira diferença nas atividades propostas. Enquanto Paroz e Saffray consideram o Método Intuitivo adequado às "áreas reais" do conhecimento, isto é, conteúdos que possibilitem percepções diretas dos sentidos, embora o apliquem também às instituições sociais, Calkins e Delon consideramno como método geral de ensino e, portanto, também aplicável à leitura, história e outros campos abstratos, pois os princípios da aprendizagem relacionam-se ao ser humano e não ao objeto. Na segunda perspectiva mencionada, as lições de coisas são um método geral de ensino ao qual todos os conteúdos devem ser submetidos. Na primeira perspectiva, as lições de coisas são concebidas como atividades que contemplam diálogos e uso didático de objetos, sendo mais adequadas a áreas específicas de conhecimento e como recurso para despertar o interesse dos alunos.

Saffray, como os outros autores, descreve o funcionamento dos sentidos e enfatiza sua utilização na aprendizagem, o que demanda ações intencionais dos professores para transformar esses órgãos naturais em instrumentos refinados para a obtenção de idéias claras e precisas:

Aqui temos algumas verdades incontroversas: os sentidos põem-nos em comunicação com o mundo exterior por intermedio de órgãos que se chamam órgãos dos sentidos. Para bem compreender as impressões produzidas pelos sentidos, é necessário reflexão e hábito. O exercício faz-nos compreender e apreciar com maior exatidão as impressões dos sentidos. (Saffray 1908, p. 333)

No entanto, as lições contidas no manual por ele elaborado recorrem constantemente a fatos presentes na memória da criança, substituindo, em 
muitas delas, a observação pela descrição. Seu livro tem início com uma lição sobre a Terra e os astros, descritos nos seguintes termos:

\begin{abstract}
As minhas primeiras palavras vão sem dúvida admirar-te: a Terra é redonda: é uma esfera, uma esfera enorme. (...) À medida que vais caminhando, a colina parece abaixar-se, a igreja parece sair da terra, mas, na realidade, tu é que vais subindo a encosta andando sobre a esfera; é este fato que te permite ver sucessivamente os objetos que se encontravam do outro lado da curvatura. (Saffray 1908, p. 8)
\end{abstract}

Nessa proposição, embora abordando um fenômeno físico, privilegiase a crença e não a observação, pois há, de visível, apenas a ilustração do livro. O conhecimento sobre a forma da Terra não ocorre com a simples observação, mas demanda equipamentos específicos para tal constatação, domínio da capacidade de abstração e conhecimentos prévios sobre formas geométricas, noções espaciais e geográficas. Embora apresentando como sugestão a atividade de caminhar para a constatação das afirmações, tratase de um recurso que apela mais à imaginação ou à memória do que à experimentação e, em qualquer dos casos, pressupõe conhecimentos aos quais o livro não faz menção.

Em outras lições há sugestão de experiências que podem ser feitas pelas crianças em casa, como, por exemplo, constatar os três estados da água pela observação de uma panela no fogo. Essa observação dá ensejo à seguinte generalização:

É o mar, com efeito, que fornece toda a água do nosso globo. O ar, aquecido pelo sol, absorve-a, dissolve-a, no estado de vapor, transportaa para toda a parte, depois deixa-a condensar sob a forma de nevoeiros, chuva ou solidificar-se sob a forma de gelo e de neve. Deste modo o nosso globo funciona como um enorme alambique. (Saffray 1908, p. 31)

A progressão do conhecimento não se dá a partir de noções e conceitos adquiridos por meio da observação, mas com base na ilustração ou apenas tendo a memória como referência (observação das próprias idéias). Assim sendo, pode-se dizer que a observação, nesse manual, é um pressuposto 
que a escola desobriga-se de fornecer mas ao qual recorre, valendo-se mais da memória que da observação para a geração de idéias novas.

Em síntese, pode-se dizer que o manual de Saffray não faz uso de objetos propriamente ditos; eles são substituídos por ilustrações e palavras. Segundo o autor, o desenho é uma linguagem universal, que possibilita a criação de idéias claras. As vantagens da imagem ou da ilustração são reafirmadas num capítulo específico no qual enfatiza-se sua potencialidade para a geração de compreensão. A tentativa de substituir a coisa concreta por sua imagem, no entanto, parece ressentir-se do pequeno progresso gráfico existente no período. As imagens apresentadas (moinhos, fábricas, construções ou acidentes geográficos e climáticos), do tipo bico de pena, são pequenas, pouco nítidas e repletas de detalhes. Mesmo na lição sobre as pedras existentes na natureza, a observação é apenas sugerida ao leitor e não utilizada como recurso didático, embora dos Museus do Dr. Saffray, material didático de apoio, faça parte a coleção de pedras. O objeto, nesse exemplar do Método de Ensino Intuitivo, é substituído por sua descrição textual detalhada ou por imagens conhecidas ou desconhecidas pelas crianças, servindo muito pouco à observação e à experimentação.

Jules Paroz, em seu manual, ressalva que o professor deve valer-se da descrição para representar objetos que não podem ser colocados diante dos olhos das crianças. Embora no início as lições de coisas incidam sobre objetos presentes na escola, tais como estrado, púlpito, cadeiras, mesas, bancos, mapas, lousa, apagador, giz, livros, cadernos, penas, lápis, régua, seu aprofundamento inclui conhecimentos sobre bebidas, ocupações e profissões, instrumentos de trabalho, as vocações, os animais, plantas etc, obedecendo à seguinte seqüência: objetos fabricados pelo homem, seguidos dos objetos naturais ou matérias-primas, finalizando com os sujeitos complexos.

Aliando o conhecimento das "coisas reais" àquele da língua materna, Paroz prescreve ao professor que a instrução deve iniciar-se com o nome dos objetos, sua classificação e partes de que são compostos, seguido da nomeação de suas qualidades e ações. Assim, após um pequeno entretenimento com os objetos, os alunos devem ocupar-se com exercícios de linguagem e frases curtas do seguinte tipo: "A rosa é uma flor"; "A rosa é branca ou rosa"; "A violeta é uma flor"; "A violeta é violeta." Na progressão dos estudos, os objetos vão deixando de estar presentes na sala de aula, passando-se a utilizar mais a memória e menos a produção de sensações, conforme o exemplo a seguir: 
Qualidades de uma casa. Uma casa pode ser nova, velha, antiga. Vermelha, branca, amarela, rosa, cinza, verde; alta, baixa, estreita, profunda, pequena, vasta, espaçosa; boa, elegante, própria, sólida. Qual a cor da escola? Ela é nova ou velha, sólida ou não sólida, baixa ou alta? Como se podem ver as qualidades da escola? Com meus olhos. $O$ que seus olhos vêem? Meus olhos vêem a cor e as qualidades da escola. (Paroz 1875, p. 80)

Calkins, com a pretensão de elaborar um manual que supere as incoerências apresentadas por aqueles já produzidos, afirma que:

Empunhar um objeto aos olhos da classe, expor a sua forma, a sua cor, o seu tamanho, o de que é feito, seu nome e utilidade, exigindo então dos alunos que repitam a explicação recebida, não é dar lição de coisas. Tão pouco fareis uma lição de coisas, se levantardes um objeto perante os discípulos, e perguntar: - Que é isto? A que reino pertence? Onde se encontra? Que serventia tem? (Calkins 1950, p. 488/9)

Para esse autor, o método intuitivo deve ser aplicado a todas as áreas de conhecimento e, iniciando suas lições sobre as formas geométricas, faz uso de objetos presentes no cotidiano da criança, progredindo até chegar a objetos industrializados e elementos naturais a partir dos quais é possível detectar a ênfase dada a um modelo social específico, qual seja, aquele pautado no trabalho industrial, portador de um modelo formativo que tem a racionalidade e a produção de objetos e mercadorias como seus valores prioritários.

O processo de transposição didática elaborado por Calkins difere daquele dos outros autores na medida em que contempla várias etapas do processo que vai dos objetos concretos à abstração que, por sua vez, permite a generalização das idéias e a elaboração do conceito.

No manual de Calkins, os objetos são os elementos sobre os quais vão ser exercitados os sentidos e o raciocínio para a aquisição do conhecimento. São objetos conhecidos pelas crianças, como bolas, laranjas, anéis, vassoura, alfinetes, ardósia, mesa, talheres etc., para que o conhecimento possa progredir daquilo que já é conhecido - o objeto - para sua forma geométrica, suas propriedades, comparação com formas 
semelhantes e diferentes. A aprendizagem das formas geométricas tem prosseguimento com as atividades, que se tornam gradualmente mais complexas e ascendendo dos objetos familiares e concretos para a abstração, isto é, para a percepção da forma em si, síntese que consiste em agrupar sob um mesmo conceito objetos variados, salientando-se suas características determinantes, bem como suas singularidades. Assim sendo, os objetos familiares às crianças são o ponto de partida e o ponto de chegada do conhecimento, embora a distância entre eles consista, justamente, no processo de formalização do saber.

Nas lições de Calkins, o elemento já conhecido pela criança, a bola, por exemplo, serve de ensejo ao exercício dos sentidos para a aprendizagem das formas geométricas e, ao final do processo, o aluno deve ser capaz de reconhecer, na bola, a circunferência, conceito que possibilita reunir na mesma categoria rodas de veículos, frutas, moedas, por meio da abstração, pré-requisito para o conhecimento daquilo que é desconhecido pelo aluno. Criticando outros autores, Calkins esclarece seus propósitos:

\begin{abstract}
Costumam alguns preceptores circunscrever as suas lições a espécies de gabinetes de curiosidades; de onde provém tornarem-se puramente mecânicos esses exercícios, assim que se acaba a novidade dos objetos que compõem a coleção. Às vezes tais espécies são raridades, que dificilmente aos meninos se deparará ensejo de ver, e não despertam a curiosidade de examinar objetos mais comuns, nem cultivam, portanto, os hábitos que hão de levar a criança a interessar-se pelo conhecimento das coisas que a rodeiam. (Calkins 1950, p. 491)
\end{abstract}

Dedicado à educação infantil, o manual produzido por Delon privilegia os objetos tanto quanto o de Calkins. É por meio de aros, bolas, bastões etc., que se desenvolvem as brincadeiras e os jogos que criam situações propícias à aquisição de noções de posição e movimento, cores, as ações produzidas sobre o objeto, suas propriedades mais aparentes, bem como a importância dos sentidos para o conhecimento dos diferentes objetos.

Embora todos os autores afirmem que a organização das lições caminhe do que é sabido para o que ignorado, do mais fácil para o mais difícil, Saffray e Paroz pautam-se claramente na visão do adulto. Ao derivar a lição sobre as pedras daquela das casas, por exemplo, Saffray revela o raciocínio subjacente à sua organização do conhecimento: mesmo que o 
material do qual são feitas as casas não seja visível e não se preste à observação das crianças, ele é um dado previamente conhecido pelos adultos mas não pelas crianças, o que não é considerado no processo didático.

Embora enfatizando as justificativas apresentadas pelos autores para a adoção do método de ensino intuitivo, deve ser comentado também o significado da introdução de novos conteúdos no currículo escolar. Do mesmo modo que o trabalho torna-se a categoria operacionalizadora da aprendizagem, são acrescentadas ao programa escolar, nesse período, áreas do conhecimento relacionadas às atividades produtivas. A valorização do saber vinculado a resultados práticos e concretos evidencia-se no grande número de atividades escolares a elas relacionadas, apresentadas nos manuais. Em alguns deles o trabalho priorizado é o dos adultos, em outros, o trabalho das crianças, embora seja constante o enaltecimento da divisão social do trabalho.

Os objetos utilizados ou descritos pelos autores de manuais são produtos provenientes do trabalho industrializado ou manufaturado, além de serem distintivos de uma classe social e, portanto, denotativos de condição econômica. O conteúdo ensinado com o nome de lições de coisas veicula uma valorização do progresso científico e das aplicações a ele relacionadas. São acrescentados ao programa escolar áreas do conhecimento relativas às atividades produtivas, tais como as ciências físicas e a geometria e suas aplicações na construção de máquinas e produtos.

\section{Cultura escolar e transposição didática}

Acreditamos que essas diferentes interpretações, fundamentadas nos mesmos princípios sobre o conhecimento, constituem fonte primária por meio das quais é possível compreender alguns elementos da cultura escolar, uma vez que expressam valores ilustrativos da seleção de conteúdos operada pela escola.

Pretende-se ressaltar ainda que a análise dos quatro manuais consignados com o nome de método intuitivo apresentam diferenças importantes e significativas no que se refere à utilização das ciência no mundo moderno e sua importância na sociedade. A análise dos passos metodológicos propostos no manual de Calkins priorizam a aquisição de algo que poderíamos chamar de raciocínio científico, isto é, a transposição didática 
por ele efetuada incide sobre a passagem do raciocínio concreto (proveniente dos próprios objetos) para o raciocínio abstrato que é a generalização dos objetos particularmente conhecidos. Toda a seqüência das lições está voltada para a passagem de um raciocínio a outro, detendo-se nas diferentes mediações que vão do objeto conhecido, sua classificação e sua diferenciação até chegar à definição ou ao conceito. Pode-se dizer que o projeto de modernização do ensino apresentado por esse autor prioriza a aquisição de hábitos mentais e de esquemas interpretativos que possibilitariam a compreensão, bem como a implementação das inovações científicas.

Nos manuais de Paroz e Saffray, cujo conteúdo assemelha-se a uma enciclopédia, a ênfase recai na aquisição dos resultados da ciência já alcançados e passíveis de serem apropriados pelos homens, se não todos, ao menos pelos de uma classe social determinada. Seus passos metodológicos iniciam-se pela definição ou pelo conceito que deve ser memorizado e generalizado, para abranger outros objetos também gravados na memória. Assim sendo, sua preocupação inicial com o ensino da ciência reveste-se de um caráter de divulgação de resultados científicos, de levar ao conhecimento do aluno as características das coisas produzidas pelo homem e menos o modo de produzi-las. Enquanto o manual de Calkins parece priorizar o raciocínio que possibilita a criação cientifica, o de Paroz é mais voltado à legitimação de valores previamente estabelecidos.

Pode-se dizer que ambos estão vinculados ao projeto modernizador da sociedade em curso no século XIX, mas aliados, cada um deles, a visões específicas do que seja o progresso: um valorizando a capacidade humana de construí-lo, e outro informando o homem sobre um suposto progresso já conquistado. Vinculados ambos ao período de apogeu do mundo burguês e do modo de produção capitalista, suas diferenças informam-nos sobre diferentes concepções de um mesmo projeto social.

Valendo-nos ainda de expressões cunhadas por Bourdieu, podemos dizer que a cultura escolar que se constitui no final do século XIX opera fornecendo referências e itinerários, conforme a expressão adotada por cada um dos autores. Afirmar que a cultura transmitida pela escola deve ser tomada como referência cultural implica balizar dados e informações, a fim de permitir que o aluno caminhe com relativa autonomia, inserindo-se num contexto que lhe precede. A cultura escolar entendida como itinerário seleciona e organiza dados e informações, determinando os pontos a serem aprendidos e os meios de fazê-lo. Ao adotar a perspectiva do itinerário, a escola existente apresentaria uma ordenação cultural e a justificativa para 
tal organização, ambas inseparáveis no processo de aquisição cultural, ambas constitutivas de uma imagem ou representação da cultura, explicitada e materializada, principalmente, nos manuais de ensino.

Afirmamos, portanto, na esteira de Forquin (1993) que, ao selecionar conteúdos e método de ensino, estamos realizando escolhas educativas que, ao final do processo, resultam numa seleção cultural e interpretativa produzida pela escola no processo de transmissão de saberes, que encontram justificativas no âmbito dos valores e do desenvolvimento do indivíduo e da sociedade, traduzidas no processo de transposição didática.

\title{
Object Lessons: Scientific conception and the modernisation project to society
}

\begin{abstract}
The objective of this article is to comprehend some aspects of the school culture, to remark the selection of cultural, economic and educational values examined by the school instruction from the analysis of didactic manuals to teachers use, which were elaborated during the last decades of XIX century and based upon the Intuitive Method or Object Lessons. Although the manuals express the same philosophical basis, they present different procedures to the teaching of the school contents which are specific views of the scientific progress. The differences presented by the manuals linked to the modernisation project of society, in progress during XIX century, inform us about several points that constitute that project.
\end{abstract}

\section{Bibliografia}

ATAS e Pareceres do Congresso da Instrução do Rio de Janeiro. Rio de Janeiro: Tipografia Nacional, 1884. FBN.

BOURDIEU, P. "Sistemas de ensino e sistemas de pensamento". In: A economia das trocas simbólicas. São Paulo: Perspectiva, 1992.

CALKINS, N. A. Primeiras lições de coisas. Tradução de Rui Barbosa. Rio de Janeiro: Ministério da Educação e Saúde, 1950. (Obras Completas, v. 13, t. 1).

CHERVEL, A. La culture scolaire. Une approche historique. Paris: Belin, 1998. 
CHEVALLARD, Y. La transposition didactique; du savoir savant au savoir enseigné. Grenoble: La Pensée Sauvage, 1985.

COMPERE, M.M. (org.). Histoire du temps scolaire en Europe. Paris: Institut National de recherche pédagogique, 1997.

DELON, F.Ch. et DELON, M.Ch. Exercices et travaux pour les enfants selon la méthode et les procedés de Pestalozzi et de Froebel. Première partie. $6^{\mathrm{a}}$ ed. Paris: Hachette, 1913.

DELON, C. Exercices et travaux pour les enfants selon la méthode et les procedés de Pestalozzi et de Froebel. Deuxième partie. Paris: Hachette, 1892.

FORQUIN, J.-C. Escola e cultura: As bases sociais e epistemológicas do conhecimento escolar. Tradução de Guacira Lopes Loro. Porto Alegre: Artes Médicas, 1993.

HOBSBAWM, E. e RANGER, T. (orgs.). A invenção das tradições. Rio de Janeiro: Paz e Terra, 1997.

PAROZ, J. Plan d'études et leçons de choses pour les enfant de six à neuf ans. $3^{\mathrm{a}}$ ed. Neuchatel: James Attinger, 1875.

PERRENOUD, Ph. La fabrication de l'excellence scolaire: Du curriculum aux pratiques d'évaluation. $2^{\mathrm{a}}$ ed. Genebra: Droz, 1995.

. "Práticas pedagógicas e profissão docente: Três facetas". In: Práticas pedagógicas, profissão docente e formação. Perspectivas sociológicas. Tradução de Helena Faria, Helena Tapada, Maria João Carvalho e Maria Nóvoa. Lisboa: Dom Quixote, 1993.

PRIMEIRA Exposição Pedagógica do Rio de Janeiro - Documentos. Rio de Janeiro: Tipografia Nacional, 1884. FBN.

SAFFRAY. Lições de cousas. Para uso das classes de instrução primária. Trad. de M.C. Mesquita Portugal. Porto: Livraria Chardron; Rio de Janeiro: Livraria Alves, 1908. 